\title{
PENGGUNAAN CARAGENAN DENGAN METODE PROSES BERBEDA (SRC DAN RC) SEBAGAI BAHAN PENGENKAPSULAT LACTOBACILLUS ACIDOPHILUS TERHADAP VIABILITAS DAN STRUKTUR MIKROKAPSUL SECARA IN VITRO
}

\author{
Oleh: \\ Dwi Setijawati*), Susinggih Wijana*), Aulani’am*), Imam santosa*) \\ *) Tenaga Pengajar Universitas Brawijaya Malang
}

\begin{abstract}
Abstrak
Caragenan jenis Eucheuma cottonii dapat digunakan sebagai bahan pengenkapsulat berdasarkan kekuatan gel. Metode proses pembuatan caragenan antara Semi Refine Caragenan (PNG) dan Refine Caragenan (Gel Press) akan mempengaruhi kekuatan gel. Kekuatan gel berbeda akan mempengaruhi kemampuan sebagai bahan pengenkapsulat terhadap viabilitas Lactobacillus acidophilus pada kondisi pH 2 dan pH 7 secara in vitro. Tujuan penelitian adalah mempelajari pengaruh penggunaan metode proses antara SRC dan RC pada kondisi $\mathrm{pH}$ berbeda terhadap viabilitas Lactobacillus acidophilus. Metode penelitian adalah laboratorium eksperimental desain, dengan perlakuan $\mathrm{A} 1=\mathrm{SRC} ; \mathrm{A} 2=\mathrm{RC} ; \mathrm{B} 1=\mathrm{pH} 2 ; \mathrm{B} 2=\mathrm{pH} 7$, bahan penelitian: Eucheuma cottonii (dari Lombok Kep), Lactobacillus acidophilus ATCC 4356;Pembuatan caragenan SRC (FMC, 1977); RC (modifikasi FMC, 1977);Pembuatan mikrokapsul dengan metode emulsi (Adhikari, 2003), Analisa data menggunakan software SPSS, viabilitas menggunakan MRS Agar metode tuang, , struktur mikrokapsul diamati menggunakan CLSM (Confocal laser Scanning Mycroscope). Hasil penelitian adalah metode proses SRC dan RC memberikan pengaruh berbeda nyata terhadap viabilitas Lactobacillus acidophilus, tertinggi pada perlakuan RC sebesar 3,348 cfu/ml (log). Interaksi perlakuan memberikan pengaruh berbeda nyata terhadap viabilitas Lactobacillus acidophilus, tertinggi didapatkan pada perlakuan RC pada kondisi pH 7 sebesar 3,476 cfu/ml (log). Disarankan menggunakan caragenan jenis Eucheuma cottonii dengan metode proses RC, tetapi konsentrasi perlu ditingkatkan untuk mencapai standar viabilitas $10^{7} \mathrm{cfu} / \mathrm{ml}$ atau $7 \mathrm{cfu} / \mathrm{ml}$ (log).
\end{abstract}

Keywords : Eucheuma cottonii, SRC dan RC, viabilitas lactobacillus acidophilus 
Salah satu hidrokoloid yang bisa digunakan sebagai bahan pengenkapsulat adalah caragenan (Wandrey et al., 2010). caragenan merupakan hasil ekstraksi Eucheuma sp. Eucheuma cottonii merupakan spesies Eucheuma sp penghasil caragenan tipe kappa. Penggunaan metoda ekstraksi dengan penambahan alkali akan meningkatkan kemampuan gelasi yang dianalisa berdasarkan kekuatan gelnya.

Pemanfaatan Kappa-caragenan dalam proses mikroenkapsulasi probiotik khususnya Lactobacillus acidophilus sebagai bahan pengenkapsulat sudah dilakukan. Klein and Vorlop (1985) menyatakan bahwa Kappacaragenan adalah polisakarida netral yang membutuhkan temperatur tinggi sebesar $60^{\circ} \mathrm{C}$ sampai $90^{\circ} \mathrm{Cuntuk}$ kelarutannya dengan konsentrasi 2-5\% , jika diaplikasikan pada proses mikroenkapsulasi. Penggunaan Eucheuma cottonii dalam bentuk kappa-caragenan dengan konsentrasi $3 \%$ dapat digunakan sebagai bahan pengenkapsulat Lactobacillus sp (Adhikari et al., 2000).

Faktor bahan pengenkapsulat dan konsentrasinya merupakan faktor penting didalam proses mikroenkapsulasi. Sifat bahan pengenkapsulat akan menentukan kemampuannya sebagai bahan pelindung Lactobacillus acidophilus (Nussinovitch, 1997). Penggunaan caragenan sebagai bahan pengenkapsulat akan dilihat berdasarkan sifat dan kekuatan gelnya. Salah satu faktor yang mempengaruhi sifat dan kekuatan gel adalah metoda proses pembuatan caragenan. Caragenan adalah hasil ekstrak dengan menggunakan metoda proses tertentu, yang hasilnya adalah peningkatan kandungan 3,6 anhidrogalaktan. Peningkatan 3,6 anhidrogalaktan akan mempengaruhi sifatnya berdasarkan kekuatan gel, dan viskositas. Sehingga penggunaan perlakuan metoda proses dan pada kondisi $\mathrm{pH}$ berbeda terhadap viabilitas Lactobacillus acidophilus perlu dilakukan dalam penelitian ini.

Tujuan Penelitian adalah mempelajari pengaruh penggunaan metode proses pembuatan caragenan jenis Eucheuma cottonii sebagai bahan pengenkapsulat pada kondisi $\mathrm{pH}$ berbeda terhadap viabilitas Lactobacillus acidophilus.

\section{Metode Penelitian}

Bahan: a)Eucheuma cottonii (dipanen dari daerah Lombok Kep, umur 42 hari); b) pembuatan caragenan dengan metode proses 
SRC (FMC, 1977) melalui langkah rumput laut dicuci bersih, dihilangkan kotoran, diekstraksi dengan $\mathrm{KOH} 6 \%$ pada suhu 75 $80^{\circ} \mathrm{C}$, penetralan, pengeringan, penggilingan; pembuatan caragenan dengan metode proses RC secara Gel Press (modifikasi FMC, 1977) melalui langkah sebagai berikut rumput laut dicuci bersih, direbus dengan larutan $\mathrm{KOH}$ pada suhu $85^{\circ} \mathrm{C}-95^{\circ} \mathrm{C}$, dihancurkan, dilanjutkan ekstraksi selama 2 jam, kemudian diturunkan $\mathrm{pH}$ nya sampai netral (pH 7- $\mathrm{pH}$ 8), disaring, dituang kedalam larutan $\mathrm{KCl}$, di press, dikeringkan, digiling, tepung caragenan; c) Pembuatan mikrokapsul Lactobacillus acidophilus (Adhikari, 2003) melalui langkah sebagai berikut: SRC/RC jenis Eucheuma cottonii dilarutkan dalam air dengan konsentrasi 1\%, kemudian dipanaskan pada suhu $96^{\circ} \mathrm{C}$ selama 5-6 menit, setelah itu dalam posisi sol diturunkan suhunya sampai $42^{\circ} \mathrm{C}$ ditambahkan $10 \mathrm{ml}$ suspensi sel Lactobacillus acidophilus dengan kepadatan $10^{9} \mathrm{cfu} / \mathrm{ml}$, campuran ini disebut dengan Phase Dispersi (DP), langkah selanjutnya menyiapkan $100 \mathrm{ml}$ minyak sayur dan emulsifier (tween 80), diaduk pada hotplate dengan stirer, dipanaskan pada suhu $42^{\circ} \mathrm{C}$, campuran ini disebut dengan Phase Continyu (CP), Campuran DP dimasukkan ke dalam CP, kemudian diaduk selama 10 menit dengan kecepatan $250 \mathrm{rpm}$, sambil

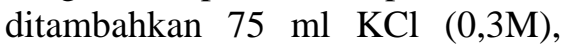
fase minyak dipindahkan dari campuran, mikrokapsul dipanen dengan sentrifugasi selama 10 menit, selanjutnya mikrokapsul dicuci dengan 0,3M $\mathrm{KCl}$ dengan 2 kali pengulangan, mikrokapsul siap dianalisa; 4) mikrokapsul Lactobacillus acidophilus yang tersalut karaginan semi murni (SRC) jenis Eucheuma spinosum masing-masing perlakuan dimasukkan ke dalam larutan $\mathrm{pH} 2$ selama 2 jam dan larutan $\mathrm{pH} 7$ selama 4 jam, kemudian dianalisa viabilitasnya dan diamati struktur mikrokapsul.

Analisa : a) Kekuatan gel (FMC, 1977); b) Sulfat (FMC, 1977); c) viskositas (FMC, 1977); d) FTIR (Simorangkir, 2004); e) viabilitas Lactobacillus acidophilus menggunkan metode tuang dengan seri pengenceran media MRSAgar.

\section{Hasil Dan Pembahasan}

Hasil analisa gugus fungsi menggunkan FTIR pada caragenan jenis Eucheuma cottonii dengan metoda proses berbeda dapat dilihat pada Gambar 1 dan Gambar 2. 


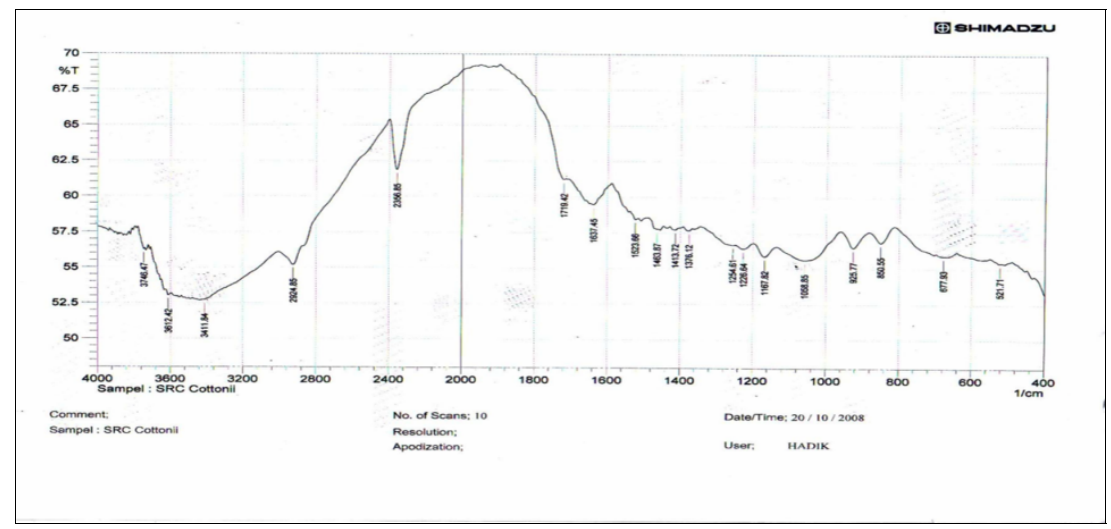

Gambar 1. Gugus fungsi SRC Eucheuma Cottonii menggunakan FTIR

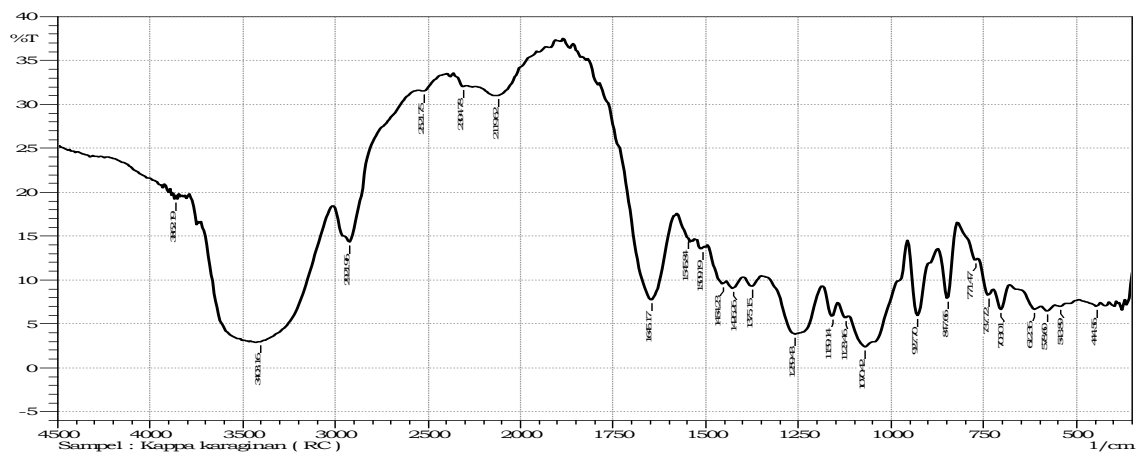

Gambar 2. Gugus fungsi RC Eucheuma Cottonii menggunakan FTIR

Dari Gambar didapatkan gugus fungsi hasil analisa yang dilakukan berturut-turut adalah gugus fungsi ester sulfat terdapat pada serapan bilangan gelombang $1258 \mathrm{~cm}^{-1}$, ikatan glikosidik pada $1070 \mathrm{~cm}^{-1}$, anhydrogalaktosa pada $937,7 \mathrm{~cm}^{-1}$, galaktosa sulfat pada $847,7 \mathrm{~cm}^{-1}$. Intensitas serapan yang ditunjukkan oleh ester sulfat, ikatan glikosidik dan galaktosa sangat kuat. Pada daerah sidik jari terdapat serapan tajam dan lebar pada panjang gelombang $1210-1260 \mathrm{~cm}^{-1}$. 
Demikian pula daerah gugus fungsi yang lain.

Dari hasil analisa tersebut dapat dikatakan bahwa Eucheuma cottonii dengan metode proses SRC dan RC akan menghasilkan caragenan tipe kappa. Pada RC puncak serapan pada bilangan gelombang yang dihasilkan lebih tajam dan lebih banyak, tetapi kandungan 3,6 AG merupakan indikator pembentukan gel.

Hal ini didukung hasil pengujian IR pada caragenan spesies Eucheuma cottonii dan
Eucheuma spinosum standar menggunakan produk Sigma. Gugus fungsi ester sulfat terdapat pada bilangan gelombang 1210$1260 \mathrm{~cm}^{-1}$, ikatan glikosidik pada 1010-1080 $\mathrm{cm}^{-1}$, anhydrogalaktosa pada $928-933 \mathrm{~cm}^{-1}$, galaktosa sulfat pada $840-850 \mathrm{~cm}^{-1}$, dan galaktosa 2 sulfat pada $800-805 \mathrm{~cm}^{-1}$. Intensitas serapan yang ditunjukkan oleh ester sulfat, ikatan glikosidik dan galaktosa sangat kuat. Gugus fungsi menggunakan caragenan standar produk Sigma ditunjukkan pada Tabel 1 (Ramaniar,1997).

Tabel 1. Panjang gelombang gugus fungsional polisakarida standar caragenan pada spektroskopi FTIR 8108 Shimadzu.

\begin{tabular}{|c|c|c|c|c|c|c|c|}
\hline & \multicolumn{7}{|c|}{ Panjang gelombang gugus fungsi (cm-1) } \\
\hline Sampel & $\begin{array}{c}\text { Ester } \\
\text { sulfat }\end{array}$ & $\begin{array}{c}\text { Ikatan } \\
\text { glikosidik }\end{array}$ & $\begin{array}{c}3,6 \\
\text { anhidro } \\
\text { D- } \\
\text { galaktan }\end{array}$ & $\begin{array}{c}\text { D- } \\
\text { galaktan } \\
-4 \text { SO4 }\end{array}$ & $\begin{array}{c}\text { D- } \\
\text { galaktan } \\
-2 \text { SO4 }\end{array}$ & $\begin{array}{c}\text { D- } \\
\text { gal- } \\
6 \mathrm{~S}\end{array}$ & $\begin{array}{c}3,6- \\
\text { anhydro } \\
\text { galaktan } \\
-2 \text { SO4 }\end{array}$ \\
\hline $\begin{array}{c}\text { Caragenan } \\
\text {-Kappa } \\
\text { (standar) }\end{array}$ & $\begin{array}{c}1261, \\
8\end{array}$ & 1068,7 & 929,8 & 844,9 & - & - & 802,5 \\
\hline $\begin{array}{c}\text { Caragenan } \\
\text {-iota } \\
\text { (standar) }\end{array}$ & 1260 & 1072,6 & 931,7 & 848,8 & - & - & 804,4 \\
\hline
\end{tabular}

Sumber : Ramaniar (1997)

Karakteristik gugus fungsi kualitas kekuatan gel yang ditandai dengan adanya kandungan 3,6 Anhydro Galaktan (3,6 AG) pada caragenan akan memberikan perbedaan pada (Matsuhasi,1990). Keberadaan AG dalam molekul menunjukkan peningkatan fleksibilitas ikatan polimer, yang akan memberikan 
kontraksi lebih besar pada struktur random coil (Therkelsen, 1993). Hal ini menunjukkan struktur dobel heliks yang penting dalam pembentukan formasi jaringan tiga dimensi yang akan mempengaruhi sifat gel. Adanya kandungan AG akan menghasilkan pembentukan gel dengan nilai kekuatan gel yang lebih tinggi seperti yang terjadi pada agar maupun caragenan (Armisen and Galatas, 2000).

Hasil analisa kualitas caragenan dengan metoda proses berbeda terhadap kekuatan gel, kadar sulfat, gelling point, viskositas dapat dilihat pada Gambar 3.

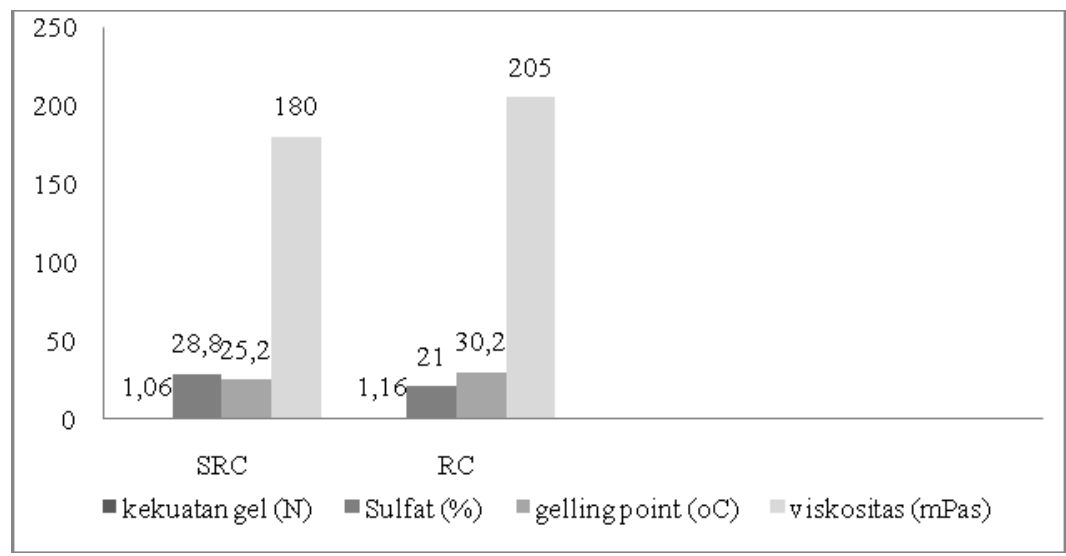

\section{Gambar 3. Kualitas caragenan spesies Eucheuma cottonii dengan metoda proses berbeda}

Hasil uji kualitas fisikokimia diatas menunjukkan bahwa metoda proses pembuatan caragenan antara SRC dan RC akan menghasilkan kualitas berbeda pula. Perbedaan metoda proses antara SRC dan RC akan mempengaruhi pemutusan ester sulfat oleh $\mathrm{KOH}$, sehingga mempengaruhi pembentukan 3,6
Anhydro-Galaktan. Kandungan 3,6 Anhydro-Galaktan akan mempengaruhi kekuatan gel (Gelstrength), gelling point, melting point, viskositasnya. Makin tinggi kandungan 3,6 Anhydro-Galaktan, makin tinggi kekuatan gel, makin rendah viskositas, makin tinggi 
gelling point, makin rendah kandungan sulfat.

Sejalan dengan pendapat Phillips and William (2001) yang mengatakan bahwa perbedaan struktur caragenan tergantung pada kandungan 3,6 AG dan ester sulfatnya. Perbedaan kedua kandungan ini akan mempengaruhi sifat hidrasi, kekuatan gel, melting point, gelling point, sineresis dan sinergisme. Perbedaan ini dipengaruhi oleh pemilihan jenis rumput laut dan metoda proses ekstraksinya. Kandungan ester sulfat dan 3,6 AG pada kappacaragenan adalah 25\% dan 34\%, sedangkan pada iota-caragenan $32 \%$ dan 30\%. Penggunaan suhu dan bahan ekstraksi yang berbeda pada kedua metode proses akan mempengaruhi pemutusan gugus ester sulfat menjadi gugus 3,6 AG. Suhu optimasi pemotongan sulfat berada pada $85^{\circ} \mathrm{C}-90^{\circ} \mathrm{C}$. Proses SRC menggunakan suhu proses ekstraksi $\quad 70-72^{\circ} \mathrm{C}$, sedangkan proses RC pada suhu $85-90^{\circ} \mathrm{C}$.
Sehingga semakin mendekati suhu proses optimal, semakin sempurna pemutusan gugus ester sulfat menjadi gugus 3,6 AG. Adanya gugus 3,6 AG akan mempengaruhi kekuatan gelnya. Penggunaan kalium pada Eucheuma cottonii akan memotong gugus ester sulfat menjadi gugus Anhydro-Galaktan.

Hasil analisa statistik menunjukkan bahwa perbedaan perlakuan metode proses pembuatan caragenan dan interaksinya memberikan pengaruh berbeda nyata $(\mathrm{P}<0.05)$, sedangkan perlakuan kondisi $\mathrm{pH}$ memberikan pengaruh tidak berbeda nyata $(\mathrm{P}>$ 0,05). Hasil analisa LSD masing masing perlakuan dapat dilihat pada Tabel 2 dan Tabel 3. Hasil uji pembeda menggunakan Uji Fisher pada confidence Level 5\% menunjukkan bahwa metode proses RC memberikan viabilitas Lactobacillus acidophilus lebih tinggi dibandingkan dengan metode proses SRC.

Tabel 2. Hasil analisa LSD perlakuan metode proses berbeda terhadap viabilitas Lactobacillus acidophilus (log/ml)

\begin{tabular}{|l|l|l|}
\hline Metode proses & Mean & SE Mean \\
\hline SRC & $2,612 \mathrm{a}$ & 0,02646 \\
\hline RC & $3,348 \mathrm{~b}$ & 0,02646 \\
\hline
\end{tabular}

*) Notasi yang didampingi huruf berbeda menunjukkan berbeda nyata $(\mathbf{P}<0,05)$ 
Sedangkan Hasil analisa LSD rata-rata pengaruh interaksi perlakuan metoda proses dan kondisi $\mathrm{pH}$ dapat dilihat pada Tabel 3. Dari tabel didapatkan bahwa viabilitas terendah didapatkan pada interaksi perlakuan metode proses
SRC pada kondisi pH 2 sebesar 2,801 $\mathrm{cfu} / \mathrm{ml}$ (log). Viabilitas tertinggi didapatkan pada interaksi perlakuan metode proses RC pada kondisi $\mathrm{pH} 7$ sebesar 3,476 cfu/ml (log).

Tabel 3. Hasil analisa LSD interaksi perlakuan metode proses dan pH berbeda terhadap viabilitas Lactobacillus acidophilus (log/ml)

\begin{tabular}{|l|l|l|l|}
\hline Metode proses & $\mathrm{pH}$ & Mean & SE Mean \\
\hline SRC & $\mathrm{pH} 2$ & 2,801a & 0,03742 \\
& $\mathrm{pH7}$ & 2,422ab & 0.03742 \\
\hline RC & $\mathrm{pH} 2$ & 3,220c & 0,03742 \\
& $\mathrm{pH7}$ & 3,476d & 0,03742 \\
\hline
\end{tabular}

*) Notasi yang didampingi huruf yang tidak sama menunjukkan berbeda nyata $(\mathbf{P}<0,05)$

SRC dan RC memberikan kemampuan berbeda didalam memberikan ketahanan terhadap viabilitas Lactobacillus acidophilus. Hal ini disebabkan karena terdapat perbedaan kualitas kekuatan gel antara SRC dan RC. Kekuatan gel makin tinggi akan memberikan viabilitas Lactobacillus acidophilus makin besar.

Beberapa bahan pembentuk gel yang umum digunakan sebagai bahan pengenkapsulat termasuk caragenan diuji berdasarkan kekuatan gelnya ( Nicetic et al., 1999). Makin besar kekuatan gel makin besar bahan enkapsulat melindungi core material.

Larutan caragenan akan kehilangan viskositas dan kekuatan gel dalam sistem $\mathrm{pH}$ dibawah 4,3. Efek ini disebabkan karena autohidrolisa yang terjadi pada $\mathrm{pH}$ rendah, dimana caragenan pada suasana asam akan memutuskan ikatan 3,6 Anhydro-Galaktosa (Hoffman, Russel and Gidley, 1996). Sehingga makin rendah sulfat, makin tinggi kekuatan gel 
dan makin besar daya tahan terhadap proses autohidrolisis. Kecepatan autohidrolisis akan seiring dengan kenaikan temperatur dan pada tingkat kation yang rendah. Caragenan akan menahan ikatan kalium sulfat apabila didinginkan dibawah titik gelling point, sehingga mengurangi autohidrolisis (William and Philips, 2001).

Penurunan $\mathrm{pH}$ akan diiikuti dengan penurunan viabilitasnya, terutama pada $\mathrm{pH}$ dibawah 1,5. Pada pH 2 selama penyimpanan 2 jam masih menunjukkan viabilitasnya, sebagian besar mikroorganisme masih tahan terhadap tekanan $\mathrm{pH}$, termasuk Lactobacilli (Blazenka and Kos et al., 2000).

Hasil pengamatan dengan Confocal Laser Scanning (CLSM) struktur mikrokapsul dapat dilihat pada Gambar 4 dan Gambar 5.
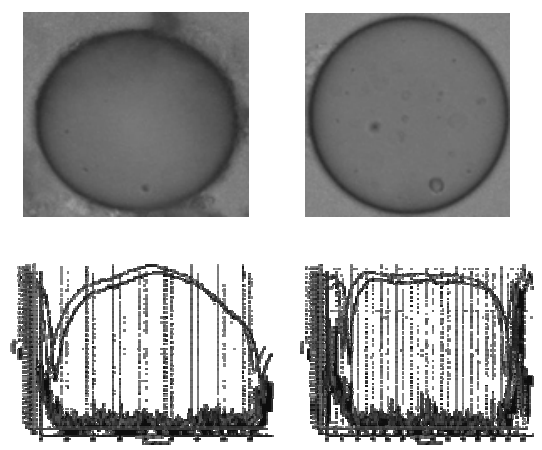

Gambar 3. Struktur mikrokapsul Lactobacillus acidophilus dengan bahan enkapsulat caragenan jenis Eucheuma cottonii metode proses SRC 

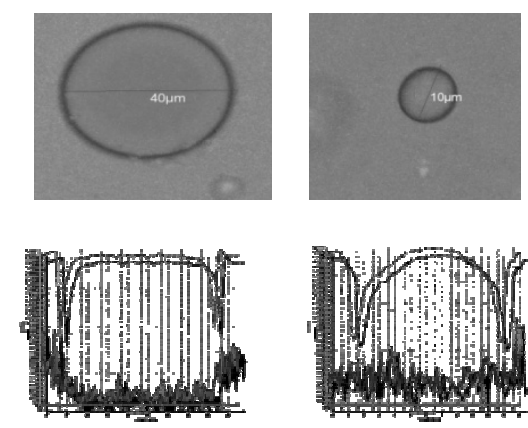

Gambar 4. Struktur mikrokapsul Lactobacillus acidophilus dengan bahan enkapsulat caragenan jenis Eucheuma cottonii metode proses RC.

Pada Gambar yang dihasilkan melalui CLSM didapatkan bahwa terdapat perbedaan layer mikrokapsul dan perubahan bentuk matriks pada grafiknya. Hal ini diduga karena perbedaan kekuatan gel, sehingga mempengaruhi perubahan layer mikrokapsul setelah diperlakukan pada $\mathrm{pH}$ berbeda.

\section{Kesimpulan}

Metode proses pembuatan caragenan antara SRC dan RC memberikan pengaruh berbeda nyata terhadap viabilitas Lactobacillus acidophilus pada kondisi berbeda, metode RC pada kondisi pH 7 memberikan rata-rata viabilitas tertinggi sebesar 3,476 $\mathrm{cfu} / \mathrm{ml}(\log )$.

\section{Saran}

Menggunakan metode proses RC untuk mendapatkan viabilitas terbaik, tetapi perlu ditingkatkan konsentrasinya untuk mendapatkan viabilitas yang sesuai dengan standar WHO $10^{7} \mathrm{cfu} / \mathrm{ml}$ atau 7 cfu/ml (log).

\section{Daftar Pustaka}

Adhikari.K, Mustapha A, 2000.

Viability

microencapsulated

bifidobacteria in set yogurt during refrigerated storage. J dairy Sci 83;1946-51

Adhikari K, and A. Mustapha. 2003. Survival and metabolic activity of microencapsulated Bifidobacterium longum in 
stirred yogurt. $J$ of Food Science. 68. 1

Armisen, R and Galatas, F. 2000. Agar. Woodhead Publishing Limited. New York Washington, DC.

Audet et al., 1988. Immobilized growing Lactic Acid Bacteria with Kappa-Carageenan and Locust Bean Gum Gel. Applied Microbiology And Biotechnology J 29;11-18.

Blazenska, Kos, B and Jagoda, 2000. Effect of protectors on the viability of Lactobacillus acidophilus M92 in simulated GastroIntestinal conditions. Food technol. Biotechnol j. 38 (2) 121-127 (2000).

FAO/WHO. 2002. Guidelines for the evaluation of Probiotics in food. London, Ontario, Canada, April 30 and May 1.

FMC Corp. 1977. Carrageenan. Marine Colloid Monograph Number One. Marine Colloids Division FMC Corporation. Springfield, New Jersey.

Hoffman, R. A., Russel A. I., and Gidley, M. J. 1996. Gums and stabilizer for the food Industry 8,137 ff., (eds) G.O, Phillips, P.A Williams and D.J Wedlock, Oxford university Press,Oxford.

Klein J, Stock J, Vorlop KD. 1985. Immobilization Techniques. Cells in : Moo-Young, M (ed) Comprehensive

Biotechnology. Vol 2. Pergaman Press. Oxford. UK. 203-224

Macfarlane S, Macfarlane GT. and Cummings JH. 2006. Review article. prebiotics in the gastrointestinal tract. Aliment Pharmacol Ther. 24,P 701714

Matsuhasi, 1990. Agar. In. harris P, Editor. Food Gels. New York: Elsevier Applied Science. P151.

Nussinovitch. A, A97. Hydrocolloid Aplication. Gum Technology in the food and other industries. The Hebrew University Of Yerussalem. Faculty of Agricultural, Food And Environmental Quality Sciences. Institute Of Biochemistry, Food Sciences and Nutrition. Rehovot, Israel. 
Blackie Academic \& Professional. An Inprint of Chapman \& Hall. LondonWeinheim-New York-TokyoMelbourne-Madras. P247-264.

Philip and William. 2001. Handbook of Hydrocolloids. CRC Press Boca raton Boston New York Washington. D.C, P 87-102.

Ramaniar, R. 1999. Karaginan type Lambda dalam Kappa karagenofit Eucheuma Alvarezii yang dibudidayakan di Indonesia. Prosidings Pra Kipnas VII Komunikasi I Ikatan Fikologi Indonesia (IFI). Serpong. Gd DRN. $\quad$ Puspiptek. 18 September 1999, P 63-75.
Simorangkir, J.H. 2004. Studi Spektra Inframerah Monosakarida. Www. digilib.si.itb.ac.id. Diakses Tanggal 20 Aprl 2008 pukul 19.00 WIB.

Therkelsen, G. H. 1993.

Carrageenan.-R.L.Whistler, J.N. BeMiller (eds).

Industrial Gums. San Diego;

Academic Press. p. 145-180.

Wandrey, C. et al., 2010. Materials

For Encapsulation. In Zuidam, N.J and V. A. Nedovic (eds.). Encapsulation technology for active food ingredients and food processing. DOI 10.1007/978-1-4419-10080_1, CSpringer Science + Business Media, LLC 2010, P.32-91. 